Article

\title{
Genetic Dissection of Azuki Bean Weevil (Callosobruchus chinensis L.) Resistance in Moth Bean (Vigna aconitifolia [Jaqc.] Maréchal)
}

\author{
Prakit Somta ${ }^{1,2,3, * \mathbb{D}}$, Achara Jomsangawong ${ }^{4}$, Chutintorn Yundaeng ${ }^{1}$, Xingxing Yuan ${ }^{1}$, \\ Jingbin Chen ${ }^{1}\left(\mathbb{D}\right.$, Norihiko Tomooka ${ }^{5}$ and Xin Chen ${ }^{1, *}$ \\ 1 Institute of Industrial Crops, Jiangsu Academy of Agricultural Sciences, 50 Zhongling Street, Nanjing 210014, \\ China; yundaeng@gmail.com (C.Y.); yxx@jaas.ac.cn (X.Y.); chenjingbin@jaas.ac.cn (J.C.) \\ 2 Department of Agronomy, Faculty of Agriculture at Kamphaeng Saen, Kasetsart University, Kamphaeng \\ Saen Campus, Nakhon Pathom 73140, Thailand \\ 3 Center for Agricultural Biotechnology (AG-BIO/PEDRO-CHE), Kasetsart University, Kamphaeng Saen \\ Campus, Nakhon Pathom 73140, Thailand \\ 4 Program in Plant Breeding, Faculty of Agriculture at Kamphaeng Saen, Kasetsart University, Kamphaeng \\ Saen Campus, Nakhon Pathom 73140, Thailand; pk_achara@hotmail.com \\ 5 Genetic Resources Center, Gene Bank, National Agriculture and Food Research Organization, 2-1-2 \\ Kannondai, Tsukuba, Ibaraki 305-8602, Japan; tomooka@affrc.go.jp \\ * Correspondence: agrpks@ku.ac.th (P.S.); cx@jaas.ac.cn (X.C.)
}

Received: 3 September 2018; Accepted: 12 November 2018; Published: 15 November 2018

\begin{abstract}
The azuki bean weevil (Callosobruchus chinensis L.) is an insect pest responsible for serious postharvest seed loss in leguminous crops. In this study, we performed quantitative trait locus (QTL) mapping of seed resistance to C. chinensis in moth bean (Vigna aconitifolia [Jaqc.] Maréchal). An $\mathrm{F}_{2}$ population of 188 plants developed by crossing resistant accession 'TN67' (wild type from India; male parent) and susceptible accession 'IPCMO056' (cultivated type from India; female parent) was used for mapping. Seeds of the $F_{2}$ population from 2014 and $F_{2: 3}$ populations from 2016 and 2017 were bioassayed with $C$. chinensis, and the percentage of damaged seeds and progress of infestation severity were measured. Segregation analysis suggested that $C$. chinensis resistance in TN176 is controlled by a single dominant gene, designated as Rcc. QTL analysis revealed one principal and one modifying QTL for the resistance, named $q \operatorname{VacBrc2} 2.1$ and $q \operatorname{VacBrc5} 5$.1, respectively. $q \operatorname{VacBrc2} 2.1$ was located on linkage group 2 between simple sequence repeat markers CEDG261 and DMB-SSR160 and accounted for $50.41 \%$ to $64.23 \%$ of resistance-related traits, depending on the trait and population. Comparative genomic analysis suggested that $q V a c B r c 2.1$ is the same as QTL Brc2.1 conferring C. chinensis resistance in wild azuki bean (V. nepalensis Tateishi and Maxted). Markers CEDG261 and DMB-SSR160 should be useful for marker-assisted selection for $C$. chinensis resistance in moth bean.
\end{abstract}

Keywords: bruchid resistance; seed weevil; Callosobruchus; insect resistance; moth bean; QTL

\section{Introduction}

The genus Vigna is an important plant taxon that contains more than 10 species cultivated as human food and animal feed. Among Vigna species, cowpea (Vigna unguiculata [L.] Walp.), mungbean (Vigna radiata [L.] Wilczek), and black gram (Vigna mungo [L.] Hepper) are internationally well-known, economically important crops, especially in Africa and Asia. Other Vigna species, such as azuki bean (Vigna angularis [Willd.] Ohwi and Ohashi), rice bean (Vigna umbellata [Thunb.] Ohwi and Ohashi), and moth bean (Vigna aconitifolia [Jaqc.] Maréchal), are grown as minor crops in several Asian and African countries. 
Bruchids or seed weevils (Coleoptera: Bruchidae) are a group of storage insects that feed on dry seeds of leguminous plants [1]. Infestation by bruchids initially occurs in the field, where female adult bruchids lay eggs on young pods; the larvae then bore through pods to the seeds, where they grow and develop into adults while consuming seed nutrients. After harvest, adult bruchids emerge from the seeds and start a secondary infestation by laying eggs directly on seeds. The first infestation usually leads to minor seed loss, while the secondary infestation can cause the total loss of a seed lot within 3 to 4 months [2]. The azuki bean weevil (Callosobruchus chinensis L.) and cowpea weevil (Callosobruchus maculatus L.) are serious bruchid pests of most Vigna species, especially cultivated ones. The azuki bean weevil is widely distributed in Asia, whereas the cowpea weevil is mainly found in Africa; however, both species are now additionally found in several other locations as a result of the international seed trade [1]. Although chemical fumigation can be used to control bruchids, this method is not practical for small-scale farmers and traders and is harmful to human health and the environment. Chemical control also increases production costs. The best way to manage bruchid infestation is by using resistant cultivars [3].

Plant breeders have long been interested in breeding cowpea, mungbean, azuki bean, and black gram for bruchid resistance. Although sources of bruchid resistance have been identified for these Vigna crops, resistant germplasm is rare. Three cowpea sources resistant to $C$. maculatus were reported by Singh [4], all of which were cultivated form and moderately resistant. Some cultivated mungbean ( $V$. radiata var. radiata) and a few wild mungbean ( $V$. radiata var. sublobata) germplasm $(<10$ accessions in total) have been found to be resistant to $C$. chinensis and $C$. maculatus [5-8]. No cultivated azuki bean (V. angularis var. angularis) or wild azuki bean (V. angularis var. nipponensis) germplasm with resistance to C. chinensis or C. maculatus have been identified [9]; however, an accession of Vigna nepalensis Tateishi and Maxted, which is very closely related to and cross-compatible with azuki bean, is able to reduce the severity of seed infestation by C. chinensis and C. maculatus [10]. Cultivated black gram (V. mungo var. mungo) is susceptible to $C$. maculatus, but its wild progenitor, $V$. mungo var. silvestris, is resistant to this bruchid [3].

Moth bean (also known as mat bean and dew bean) is one of the most heat- and drought-tolerant leguminous crops. Moth bean is grown in drought-prone, semi-arid, and arid areas of India, Afghanistan, Pakistan, Nepal, Sri Lanka, Myanmar, and some African countries. This crop can grow in harsh climates with daytime temperatures up to $45^{\circ} \mathrm{C}$ and annual rainfall of 200 to $300 \mathrm{~mm}$ [11]. India is the largest producer of moth bean, with a production area of $1.5 \mathrm{Mha}$. The main cultivation area encompasses arid regions of the state of Rajasthan [11], where moth bean is the most widely grown drought-tolerant legume. Seeds and young pods of moth bean are consumed by humans, while leaves and stalks are used as animal feed in the form of forage and hay [12]. Dry seeds of moth bean contain $23 \%$ to $25 \%$ protein. Sprouts of moth bean seeds are also consumed as a vegetable for their vitamins and minerals.

Although moth bean is a highly heat- and drought-tolerant crop that greatly benefits impoverished people in arid regions, it is extremely susceptible to insect pests, including bruchids $[13,14]$. The bruchid species most damaging to moth bean are C. chinensis and C. maculatus. Breeding for resistance to these bruchids is an important goal in moth bean breeding, but no source of resistance had previously been identified for this crop. Recently, however, an accession of wild moth bean was found to be highly resistant to $C$. chinensis. The resistance gene(s) in wild moth bean is useful for breeding a new moth bean with $C$. chinensis resistance. In this study, we conducted the first-ever molecular genetic analysis of moth bean seed resistance to $C$. chinensis. Our objectives were two-fold: (i) to determine the mode of inheritance of moth bean seed resistance to C. chinensis and (ii) to locate quantitative trait loci (QTLs) for this resistance trait. 


\section{Materials and Methods}

\subsection{Plant Materials}

An $\mathrm{F}_{2}$ population of 188 plants derived from self-pollination of a single $\mathrm{F}_{1}$ plant of a cross between 'TN67' and 'IPCMO056' was used in this study. In this cross, TN67 and IPCMO056 were used as male and female parents, respectively. The $\mathrm{F}_{2}$ population was previously used to construct a SSR-based linkage map and identify QTLs for domestication syndrome in moth bean [15]. TN67, a wild moth bean collected in India, is resistant to C. chinensis, while IPCMO056 is a cultivated moth bean from India that is susceptible to $C$. chinensis. Compared with susceptible moth bean accessions, TN67 exhibits fewer damaged seeds and a slower progress of seed damage due to $C$. chinensis.

$\mathrm{F}_{2}$ plants and four plants of each parent were grown under field conditions at the National Agricultural and Food Research Organization, Tsukuba, Japan, from July to September 2014. Spacing between plants was $1 \mathrm{~m}$. Seeds of each $\mathrm{F}_{2: 3}$ plant were harvested separately and used for bruchid resistance evaluation. In addition to the $F_{2}$ population, the $F_{2: 3}$ population and parents were grown in a nonreplicated experiment during February to May (summer) of 2016 at the Chai Nat Field Crops Research Center (CNFRC), Chai Nat, Thailand. Each entry comprising 10 plants was grown in a 6-m-long row. Spacing between rows was $0.75 \mathrm{~m}$, with plants in a row spaced $0.5 \mathrm{~m}$ apart. This population is hereafter referred to as $\mathrm{F}_{2: 3}-\mathrm{A}$. Seeds of each $\mathrm{F}_{2: 3}$ plant were harvested separately. In addition, another $\mathrm{F}_{2: 3}$ population (population $\mathrm{F}_{2: 3}-\mathrm{B}$ ) was grown together with the parents in a nonreplicated experiment during December 2016 to March 2017 at the CNFRC. Planting, spacing, and harvesting were the same as for population $\mathrm{F}_{2: 3}-\mathrm{A}$.

\subsection{Evaluation of Seeds for Bruchid Resistance}

Callosobruchus chinensis was used for seed resistance evaluation. The insects were reared on seeds of susceptible mungbean cultivar 'Kamphaeng Saen $1^{\prime}$ and kept at $30{ }^{\circ} \mathrm{C}$ and $70 \%$ relative humidity $(\mathrm{RH})$. Before evaluation for C. chinensis resistance, 100-seed weights of each plant were determined. Evaluation for C. chinensis resistance followed the method described by Somta [16] with minor modifications. In the $\mathrm{F}_{2}$ population, 30 to 40 seeds from each plant were placed in a plastic box. Ten pairs (10 males and 10 females) of newly emerged C. chinensis adults were then introduced into the box for egg laying and removed after 7 days. The infested seeds were maintained at $30^{\circ} \mathrm{C}$ and $60 \% \mathrm{RH}$. Seeds of each parent were included in the resistance evaluation, and two technical replicates was conducted. The number of bruchid-damaged seeds was counted at 23 days after infestation (DAI) and then every 3 days until 56 DAI. After each count, damaged seeds were removed from the boxes. The cumulative number of seeds damaged by bruchids at each time point was calculated and converted into a percentage. The percentage of damaged seeds was then used to calculate the area under the disease progress curve (AUDPC), which reflects the progress of the development of disease severity in plants [17]. AUDPC, which was thus an indicator of the progress of infestation severity (bruchid developmental period) in this study, was calculated as follows

$$
A U D C P=\sum_{i=1}^{n=1} \frac{y_{i}+y_{i+1}}{2} \times\left(t_{i+1}-t_{i}\right)
$$

where $y_{i}$ is the percentage of damaged seeds at the $i^{\text {th }}$ observation, $t_{i}$ is the number of days at the $i^{\text {th }}$ observation, and $n$ is the total number of observations.

For the $\mathrm{F}_{2: 3}-\mathrm{A}$ population, $\mathrm{F}_{4}$ seeds from each $\mathrm{F}_{2: 3}$ plant and the parents were evaluated separately for resistance. Forty seeds of each plant were evaluated for resistance in the same manner as described for $\mathrm{F}_{2}$ plants, expect that the percentage of damaged seeds was only recorded at 60 DAI. Two technical replicates were performed. The average percentages of damaged seeds of each family were used for data analysis. 
In the case of the $\mathrm{F}_{2: 3}$-B population, two sets of seeds (I and II) were evaluated for resistance. In set I, only the percentage of damaged seeds was determined, whereas both this percentage and AUDPC were calculated in set II. In set I, 40 seeds of each plant per line were separately evaluated for resistance as described for $\mathrm{F}_{2}$ plants, except that the percentage of damaged seeds was determined at 60 DAI. The average percentage of damaged seeds of each line was used for data analysis. In set II, seeds of all plants of a given line (10 seeds each) were bulked and evaluated for bruchid resistance as described for $F_{2}$ plants with the following modifications, the percentage of damaged seeds was determined at $60 \mathrm{DAI}$, and the number of bruchid-damaged seeds was counted at 25 DAI and then every 5 days until 60 DAI.

\subsection{Correlation Analysis and Determination of the Mode of Inheritance of Resistance}

Correlations between the percentage of damaged seeds and AUDPC and between the percentage of damaged seeds / AUDPC and 100-seed weight were assessed using R 2.0.10 [18].

The mode of inheritance of bruchid resistance was determined in the $F_{2}$ and $F_{2: 3}$ populations for two traits: percentage of damaged seeds and AUDPC. On the basis of the percentage of damaged seeds, $\mathrm{F}_{2}$ plants and $\mathrm{F}_{2: 3}$ lines were classified as resistant or susceptible following Somta et al. [16]. $\mathrm{F}_{2}$ plants and $\mathrm{F}_{2: 3}$ lines having $0 \%$ to $80 \%$ damaged seeds were considered to be resistant, which included both homozygous resistant (highly resistant, with $0 \%$ to $20 \%$ damaged seeds) and heterozygous resistant (moderately resistant, with $21 \%$ to $80 \%$ damaged seeds) genotypes, while those having $81 \%$ to $100 \%$ damaged seeds were considered as susceptible. Chi-square $\left(\chi^{2}\right)$ testing was conducted to determine the 3:1 (resistant:susceptible) ratio goodness of fit under a single gene model using R 2.0.10 [18].

To examine the inheritance of AUDPC, the $\mathrm{F}_{2}$ plants and $\mathrm{F}_{2: 3}$ lines were also classified into two categories. Plants/lines showing AUDPs of 0 to 2040 were classified as resistant, while those showing AUDPC values higher than 2040 were considered to be susceptible. A $\chi^{2}$ test was conducted as described above.

\subsection{Estimation of the Heritability of Resistance}

The broad-sense heritability $\left(H^{2}\right)$ of the percentage of damaged seeds and/or AUDPC in $\mathrm{F}_{2}$, $\mathrm{F}_{2: 3}-\mathrm{A}$, and $\mathrm{F}_{2: 3}-\mathrm{A}$ populations was calculated according to the formula

$$
H^{2}=\frac{\sigma_{F_{2}}^{2}-\left(\frac{\sigma_{P_{1}}^{2}+\sigma_{P_{2}}^{2}}{2}\right)}{\sigma_{F_{2}}^{2}} \mathrm{~h}^{2}=\frac{\sigma_{F_{2}}^{2}-\left(\frac{\sigma_{P_{1}}^{2}+\sigma_{P_{2}}^{2}}{2}\right)}{\sigma_{F_{2}}^{2}}
$$

where $\sigma_{F_{2}}^{2}$ is the variance of the $\mathrm{F}_{2}$ or $\mathrm{F}_{2: 3}$ population, $\sigma_{P_{1}}^{2}$ is the variance of ICPMO056 and $\sigma_{P_{2}}^{2}$ is the variance of TN67.

\subsection{Quantitative Trait Loci Analysis}

The $\mathrm{F}_{2}$ population used in this study was previously genotyped with 169 simple sequence repeat (SSR) and three morphological markers, which were used to construct a linkage map containing 11 linkage groups (LGs) (Yundaeng et al., 2018) [15]. The map and genotypic data were used for QTL analysis in the present study. The percentage of damaged seeds and AUDPC were applied to locate QTLs for bruchid resistance. The QTL analysis was conducted using the inclusive composite interval mapping (ICIM) method [19] as implemented in the program QTL IciMapping 4.1. A walking speed of $1 \mathrm{cM}$ and a probability in stepwise regression (PIN) of 0.001 were used for the ICIM. Significant logarithm of odds (LOD) thresholds for QTLs for each trait were determined by a 10,000 permutation test at $p=0.001$.

In addition to QTLs for bruchid resistance, QTLs for seed weight were also identified in the $\mathrm{F}_{2}$ and $\mathrm{F}_{2: 3}$ populations by ICIM using the same procedures as for bruchid resistance. This analysis was conducted to determine the genetic relationship between seed weight and bruchid resistance. 
2.6. Comparative Genomic Analysis of Bruchid-Resistance QTLs in Moth Bean, Mungbean and Wild Azuki Bean Relatives

The genomic region harboring detected QTLs for $C$. chinensis resistance in moth bean were compared with reported genes/QTLs for $C$. chinensis resistance in mungbean (V. radiata) [20] and $V$. nepalensis [10], a wild form of azuki bean (V. angularis), using common DNA markers and DNA marker locations on physical maps of mungbean and azuki bean. The physical locations of DNA markers were determined by BLASTN searching against reference genome sequences of mungbean ([21] http:/ / plantgenomics.snu.ac.kr/mediawiki-1.21.3/index.php/Main_Page) and azuki bean ([22]; http:/ / viggs.dna.affrc.go.jp). The C. chinensis resistance QTLs in moth bean were also compared with reported genes/QTLs for C. maculatus resistance in black gram (Souframanien et al., 2010) and rice bean [23].

\section{Results}

\subsection{Variation in Callosobruchus chinensis Resistance in Parents and $F_{2}$ and $F_{2: 3}$ Generations}

TN67 and IPCMO056 exhibited contrasting phenotypes for two traits related to C. chinensis resistance, namely, the percentage of damaged seeds and the progress of damage severity (the developmental period of bruchid adults) (Figure 1). With respect to the first trait, TN67 had a much lower percentage of damaged seeds than IPCMO056, with values of $6.6 \%$ to $21.6 \%$ vs. $95.4 \%$ to $100 \%$, respectively, depending on the growing environment (Table 1). The average value of this trait across growing environments and tests was $11.9 \%$ for TN67 and 98.1\% for IPCMO056. The percentage of damaged seeds in the $\mathrm{F}_{2}$ population ranged from $0 \%$ to $100 \%$, with an average of $41.6 \%$ (Table 1 ). Similarly, the percentage of damaged seeds in the $\mathrm{F}_{2: 3}-\mathrm{A}$ population ranged from $3.5 \%$ to $99.6 \%$, with an average of $57.0 \%$ (Table 1 ). Two sets of seeds were evaluated for resistance in the $\mathrm{F}_{2: 3}-\mathrm{B}$ population; the percentage of damaged seeds in set I varied between $0.5 \%$ to $100 \%$, with an average of $53.1 \%$, while that of set II ranged between $1.0 \%$ to $100 \%$, with an average of $52.2 \%$ (Table 1 ).
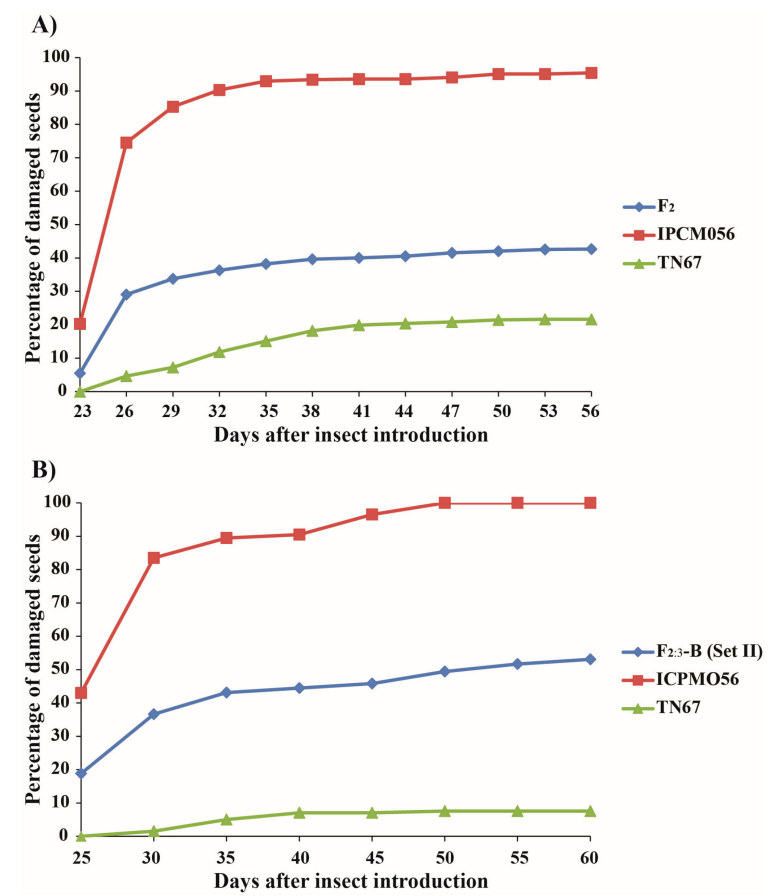

Figure 1. Patterns of Callosobruchus chinensis infestation of seeds of moth bean accessions TN67 and IPCMO056 and their derivative $\mathrm{F}_{2}$ population as reflected by the percentage of damaged seeds (A) and the area under the disease progress curve (AUDPC) (B). 
Table 1. Variation and heritability of the percentage of damaged seeds and the area under the disease progress curve (AUDPC) (progress of infestation severity) due to Callosobruchus chinensis (azuki bean weevil) in IPCMO056, TN67 and IPCMO056 $\times$ TN67 $F_{2}$ and $F_{2: 3}$ populations.

\begin{tabular}{ccccccc}
\hline \multirow{2}{*}{ Population } & \multicolumn{3}{c}{ Percentage of Damaged Seeds } & \multicolumn{3}{c}{ AUDPC } \\
\cline { 2 - 7 } & Min-Max & Mean & Heritability (\%) & Min-Max & Mean & Heritability (\%) \\
\hline IPCMO056 & $95.4-100$ & 98.1 & - & $2826.0-3158.0$ & 2992.0 & - \\
TN67 & $6.6-21.6$ & 11.9 & - & $197.0-500.0$ & 348.5 & - \\
F 2 population & $0.0-100$ & 41.6 & 83.60 & $0.0-3103.1$ & 1163.2 & 85.99 \\
$\mathrm{~F}_{2: 3}$ population (2016) & $3.5-99.6$ & 57.0 & 90.42 & & Not determined & \\
$\mathrm{F}_{2: 3}$ population (2017) (Set I) & $0.5-100$ & 53.1 & 96.03 & $16.4-3385.0$ & 1536.7 & 98.65 \\
$\mathrm{~F}_{2: 3}$ population (2017) (Set II) & $1.0-100$ & 52.2 & 99.97 & \multicolumn{3}{c}{ Not determined } \\
\hline
\end{tabular}

In terms of the progress of damage severity, AUDPCs of TN67 and IPCMO056 were correspondingly 197.0 to 500.0 , with an average of 348.5 , and 2826.0 to 3158.0 , with an average of 2992.0 (Table 1). This result indicates that seeds of TN67 were damaged much more slowly than those of IPCMO056 (a longer bruchid adult developmental period). AUDPC in the $\mathrm{F}_{2}$ population ranged from 0 to 3103.1, with average of 1163.2, while that in the $\mathrm{F}_{2: 3}-\mathrm{B}$ population varied from 16.4 to 3385.0, with an average of 1536.7 (Table 1).

The frequency distribution of the percentage of damaged seeds was trimodal and discontinuous in the $F_{2}$ population, but was trimodal and continuous in the $\mathrm{F}_{2: 3}$ ones (Figure 2A). Similarly, AUDPCs in the $\mathrm{F}_{2}$ and $\mathrm{F}_{2: 3}$ populations displayed trimodal and continuous distribution patterns (Figure 2B). The frequency distribution of both traits suggests that resistance to C. chinensis in moth bean TN67 is controlled by one or a few genes with quantitative expression.

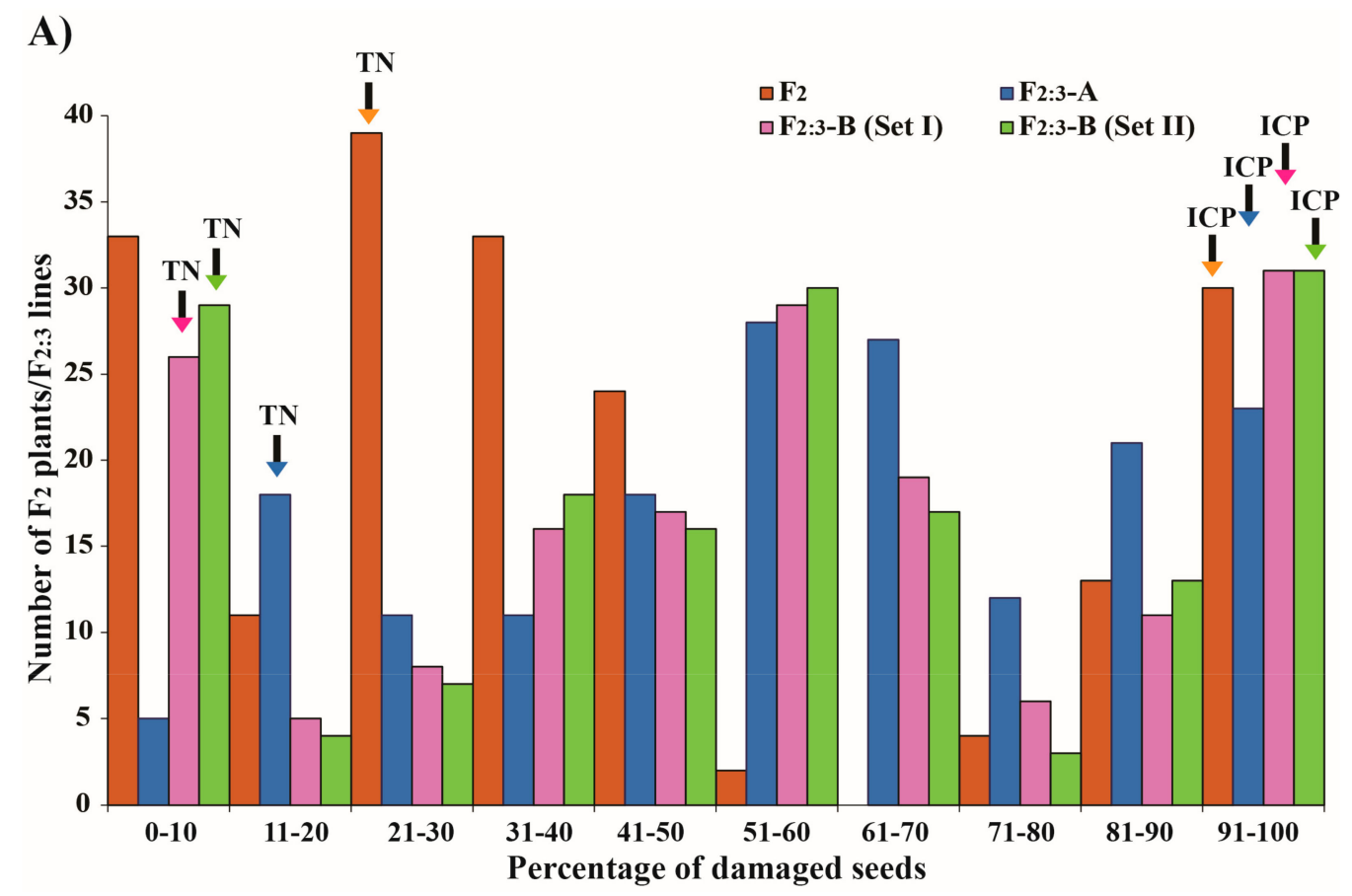

Figure 2. Cont. 


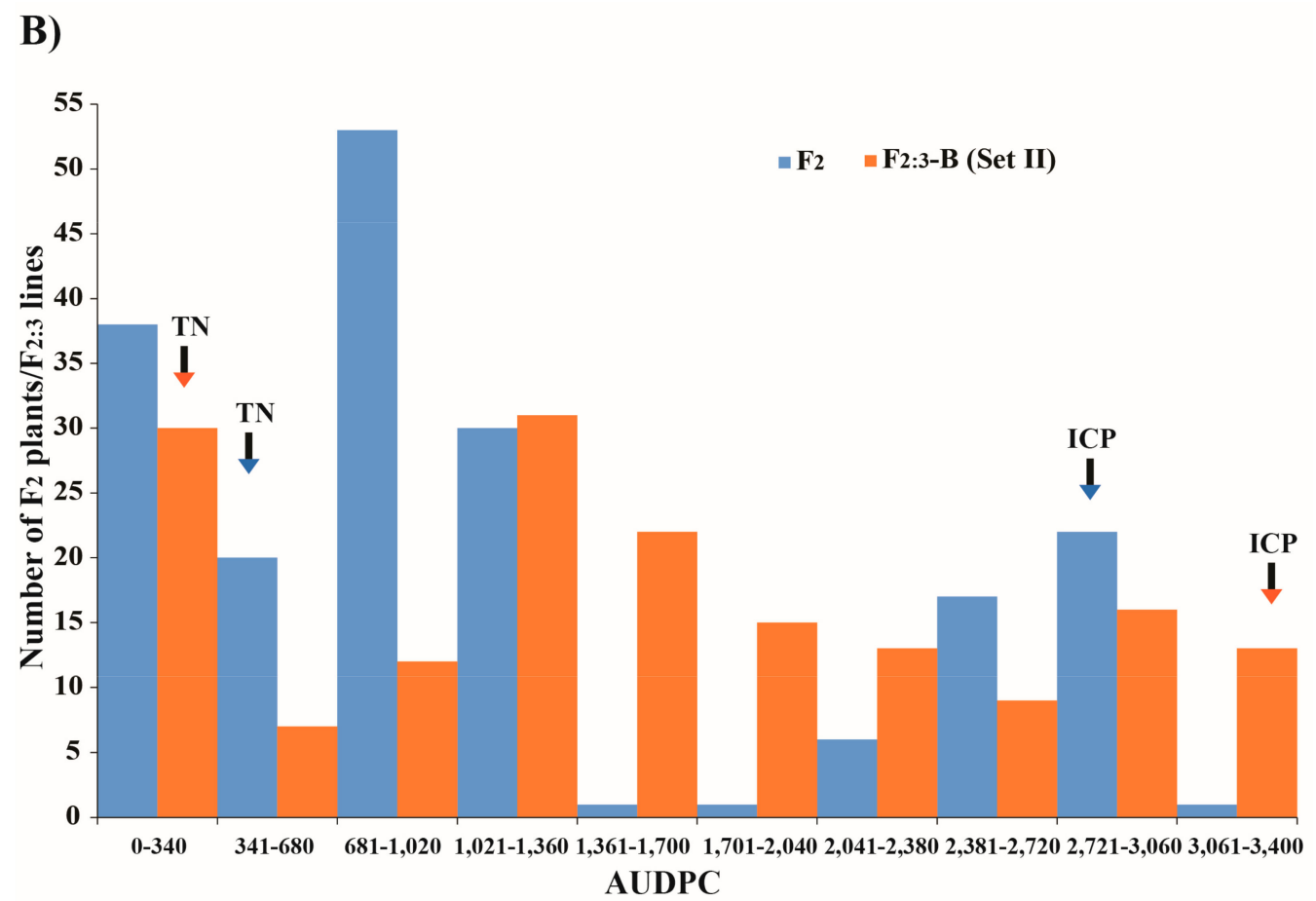

Figure 2. Frequency distribution of the percentage of damaged seeds (A) and the AUDPC (B) due to $C$. chinensis in moth bean $\mathrm{F}_{2}$ and $\mathrm{F}_{2: 3}$ populations derived from an IPCMO056 $\times$ TN67 cross.

\subsection{Correlations among Traits}

A nearly perfect correlation was observed between the percentage of damaged seeds and AUDPC in both the $\mathrm{F}_{2}$ and $\mathrm{F}_{2: 3}-\mathrm{B}$ populations: $r=0.99$ (d.f. $=185, p<0.0001$ ) and $r=0.99$ (d.f. $=164, p<0.0001$ ), respectively. This result suggests that these two traits are controlled by the same gene(s).

A low but significant positive correlation was found between the percentage of damaged seeds and 100-seed weight in the $\mathrm{F}_{2}$ population $(r=0.22$, d.f. $=185, p=0.0028)$, but no significant correlation between the two traits was detected in the $\mathrm{F}_{2: 3}-\mathrm{A}$ and $\mathrm{F}_{2: 3}-\mathrm{B}$ populations $(r=0.07$, d.f. $=151, p=0.4070$ and $r=0.11$, d.f. $=164, p=0.1693$, respectively). Similarly, a weak but significant positive correlation was observed between AUDPC and 100-seed weight in the $\mathrm{F}_{2}$ population $(r=0.23$, d.f. $=185$, $p=0.0014)$, but no significant correlation was found between these traits in the $\mathrm{F}_{2: 3}$ - $\mathrm{B}$ population $(r=0.10$, d.f. $=164, p=0.1789$, respectively $)$.

\subsection{Segregation Analysis and Heritability of Resistance}

A $\chi^{2}$ test for the percentage of damaged seeds revealed that the segregation of this trait in the $\mathrm{F}_{2}$ population and in an $\mathrm{F}_{2: 3}$ population grown in 2016 and 2017 fit a 3:1 (resistance: susceptible) ratio (Table 2). In the case of AUDPC, a $\chi^{2}$ test indicated that this trait segregated in a 3:1 (resistance: susceptible) ratio in both the $\mathrm{F}_{2}$ and $\mathrm{F}_{2: 3}$ populations (Table 2). These results suggest that seed resistance to $C$. chinensis in moth bean TN67 is controlled by a single dominant locus. We accordingly named this locus Resistance to Callosobruchus chinensis (Rcc).

The calculated broad-sense heritability of the percentage of damaged seeds in $\mathrm{F}_{2}, \mathrm{~F}_{2: 3}-\mathrm{A}$, and $\mathrm{F}_{2: 3}-\mathrm{B}$ (sets I and II) populations was very high, varying from $83.60 \%$ to $99.97 \%$ (Table 1 ). The heritability calculated for AUDPC in $\mathrm{F}_{2}$ and $\mathrm{F}_{2: 3}-\mathrm{B}$ (set I) populations was also very high, $85.99 \%$ and $98.65 \%$, respectively (Table 1). These results indicate that seed resistance to C. chinensis in moth bean TN67 is principally controlled by one or more genetic factors. 
Table 2. Chi-square test under a single gene model for the percentage of damaged seeds (\% damaged seeds) and the AUDPC due to $C$. chinensis in moth bean $F_{2}$ and $F_{2: 3}$ populations derived from an IPCMO056 $\times$ TN67 cross.

\begin{tabular}{ccccc}
\hline Population & Trait & $\begin{array}{c}\text { No. of Plants/Lines } \\
\text { Tested }\end{array}$ & $\begin{array}{c}\text { Resistant: } \\
\text { Susceptible }\end{array}$ & $\begin{array}{c}\text { Chi-Square } \\
\text { ( } \boldsymbol{p} \text { Value })\end{array}$ \\
\hline $\mathrm{F}_{2}$ & \% damaged seeds & 187 & $143: 44$ & $0.2157(0.6423)$ \\
& AUDPC & 187 & $142: 45$ & $0.0873(0.7676)$ \\
$\mathrm{F}_{2: 3}-\mathrm{A}^{1}$ & \% damaged seeds & 172 & $125: 47$ & $0.4961(0.4812)$ \\
$\mathrm{F}_{2: 3}-\mathrm{B}^{2}$ (set I) & $\%$ damaged seeds & 166 & $121: 45$ & $0.3936(0.5304)$ \\
$\mathrm{F}_{2: 3}-\mathrm{B}^{2}$ (set II) & \% damaged seeds & 166 & $122: 44$ & $0.2880(0.6541)$ \\
& AUDPC & 166 & $116: 50$ & $2.3213(0.1276)$ \\
\hline
\end{tabular}

${ }^{1}$ The $\mathrm{F}_{2: 3}$ population was grown from February to May 2016. ${ }^{2}$ The $\mathrm{F}_{2: 3}$ population was grown from December 2016 to March 2017.

\subsection{QTL Analysis}

ICIM identified two QTLs for the percentage of damaged seeds (Table 3, Figures 3 and 4). These QTLs were named qVacPDS2.1 and qVacPDS5.1. qVacPDS2.1 was consistently identified in all populations/environments, while qVacPDS5.1 was identified in only one population. qVacPDS2.1 was located between 90 and $91 \mathrm{cM}$ and was flanked by markers CEDG261 and DMB-SSR160 on LG2. This QTL accounted for $50.41 \%$ to $64.23 \%$ of the variation in the percentage of damaged seeds; it showed an additive effect of $32.91 \%$ to $42.64 \%$ and a dominant effect of $0.10 \%$ to $-11.16 \%$. qVacPDS5.1 was located at $17 \mathrm{cM}$ between markers CEDG264 and VES0664 on LG5; it explained $12.19 \%$ of the trait variation and showed an additive effect of $0.51 \%$ and a dominant effect of $22.76 \%$. At both QTLs, one or more alleles from IPCMO056 decreased the percentage of damaged seeds.

In the case of AUDPC, which was evaluated in $\mathrm{F}_{2}$ and $\mathrm{F}_{2: 3}-\mathrm{B}$ (set I) populations, ICIM consistently identified a single major QTL for this trait (Table 3, Figures 3 and 4). We named this QTL qVacAUDPC2.1. The position of $q V a c A U D P C 2.1$ was the same as that of $q V a c P D S 2.1$. qVacAUDPC2.1 explained $50.41 \%$ and $58.78 \%$ of the total AUDPC variation in the $\mathrm{F}_{2}$ and $\mathrm{F}_{2: 3} \mathrm{~B}$ (set I) populations, respectively; it possessed additive effects of 1273.19 and 1279.74 and dominant effects of -483.39 and -90.70 in the $\mathrm{F}_{2}$ and F2:3-B (set I) populations, respectively. At this QTL, one or more alleles from IPCMO056 decreased the AUDPC value. Given that the locations and effects of QTLs qVacPDS2.1 and qVacAUDPC2.1 were the same, we considered them to be the same locus and named this locus qVacBrc2.1.

In regard to 100-seed weight, which was measured in three populations, ICIM identified as many as 11 QTLs for this trait (Table 3 and Figure 3). The QTLs were distributed on LGs 1 to 7 . Depending on the population and environment, these QTLs explained $4.80 \%$ to $26.84 \%$ of the total trait variation and showed additive effects of 0.07 to 0.14 and dominant effects of -0.05 to 0.04 . 
Table 3. Quantitative trait loci (QTLs) detected by inclusive composite interval mapping (ICIM) for the percentage of damaged seeds (\% damaged seeds) and the AUDPC due to $C$. chinensis and 100-seed weight in moth bean $F_{2}$ and $F_{2: 3}$ populations from the cross IPCMO056 $\times$ TN67.

\begin{tabular}{|c|c|c|c|c|c|c|c|c|c|}
\hline Population & Trait & $\mathrm{LG}^{\mathrm{a}}$ & QTL name & Position $b$ & Franking Markers & LOD & $\operatorname{PVE}^{c}(\%)$ & Add $^{d}$ & Dom $^{e}$ \\
\hline \multirow{6}{*}{$\mathrm{F}_{2}$} & $\%$ damaged seeds & 2 & qVacPDS2.1 & 91 & CEDG261-DMB-SSR160 & 69.55 & 62.98 & 42.64 & -11.16 \\
\hline & AUDPC & 2 & qVacAUDPC2.1 & 91 & CEDG261-DMB-SSR160 & 82.20 & 63.00 & 1273.19 & -483.39 \\
\hline & 100-seed weight & 3 & $q V a c S D W 3.1$ & 22 & VES084-CEDG155 & 3.72 & 6.48 & 0.10 & 0.01 \\
\hline & & 4 & qVacSDW4.2 & 65 & CEDG091-CEDG165 & 6.38 & 11.11 & 0.14 & -0.02 \\
\hline & & 5 & qVacSDW5.1 & 0 & CEDG020-VES0091 & 5.28 & 9.01 & 0.11 & -0.03 \\
\hline & & 6 & qVacSDW6.2 & 71 & CEDG146-сp09781 & 7.25 & 15.56 & 0.15 & -0.02 \\
\hline \multirow[t]{7}{*}{$\mathrm{F}_{2: 3}-\mathrm{A}$} & $\%$ damaged seeds & 2 & qVacPDS2.1 & 90 & CEDG261-DMB-SSR160 & 40.22 & 50.41 & 32.91 & 2.98 \\
\hline & & 5 & qVacPDS5.2 & 17 & CEDG264-VES0664 & 14.54 & 12.19 & 0.51 & 22.76 \\
\hline & 100 -seed weight & 2 & qVacSDW2.1 & 36 & CDEG297-CEDG250 & 4.66 & 7.93 & 0.09 & -0.01 \\
\hline & & 3 & qVacSDW3.2 & 45 & VES0053-CEDG084 & 7.49 & 11.82 & 0.09 & 0.04 \\
\hline & & 4 & qVacSDW4.1 & 32 & Bms-VES0675 & 14.01 & 26.84 & 0.14 & -0.03 \\
\hline & & 5 & qVacSDW5.2 & 18 & VES0664-CEDG027 & 4.86 & 7.66 & 0.07 & 0.03 \\
\hline & & 6 & qVacSDW6.1 & 20 & CEDG169-CEDG034 & 3.65 & 5.80 & 0.67 & 0.01 \\
\hline \multirow[t]{8}{*}{$\mathrm{F}_{2: 3}-\mathrm{B}($ Set I) } & $\%$ damaged seeds & 2 & $q V a c P D S 2.1$ & 91 & CEDG261-DMB-SSR160 & 46.79 & 61.32 & 41.42 & 0.73 \\
\hline & AUDPC & 2 & qVacAUDPC2.1 & 91 & CEDG261-DMB-SSR160 & 44.90 & 58.73 & 1279.74 & -90.70 \\
\hline & 100-seed weight & 1 & $q V a c S D W 1.1$ & 2 & CEDG149-CEDC007 & 4.51 & 6.75 & 0.08 & 0.03 \\
\hline & & 3 & qVacSDW3.2 & 55 & VR169-VES0070 & 6.98 & 14.01 & 0.11 & 0.01 \\
\hline & & 4 & qVacSDW4.1 & 28 & Bms-VES0675 & 8.43 & 16.03 & 0.11 & -0.05 \\
\hline & & 4 & qVacSDW4.2 & 63 & CEDG091-CEDG165 & 4.22 & 6.24 & 0.07 & -0.01 \\
\hline & & 5 & qVacSDW5.1 & 0 & CEDG020-CEDG091 & 3.61 & 4.80 & 0.06 & -0.01 \\
\hline & & 7 & qVacSDW7.1 & 19 & CEDG174-CEDG215 & 5.23 & 8.46 & 0.83 & 0.01 \\
\hline $\mathrm{F}_{2: 3}-\mathrm{B}$ (Set II) & $\%$ damaged seeds & 2 & qVacPDS2.1 & 91 & CEDG261-DMB-SSR160 & 47.97 & 64.23 & 40.98 & 0.10 \\
\hline
\end{tabular}

${ }^{a}$ LG: Linkage group; ${ }^{b}$ position on the linkage group (centimorgans); ${ }^{c}$ phenotypic variance explained by the $Q T L ;{ }^{d}$ additive effect; ${ }^{\mathrm{e}}$ dominant effect. 


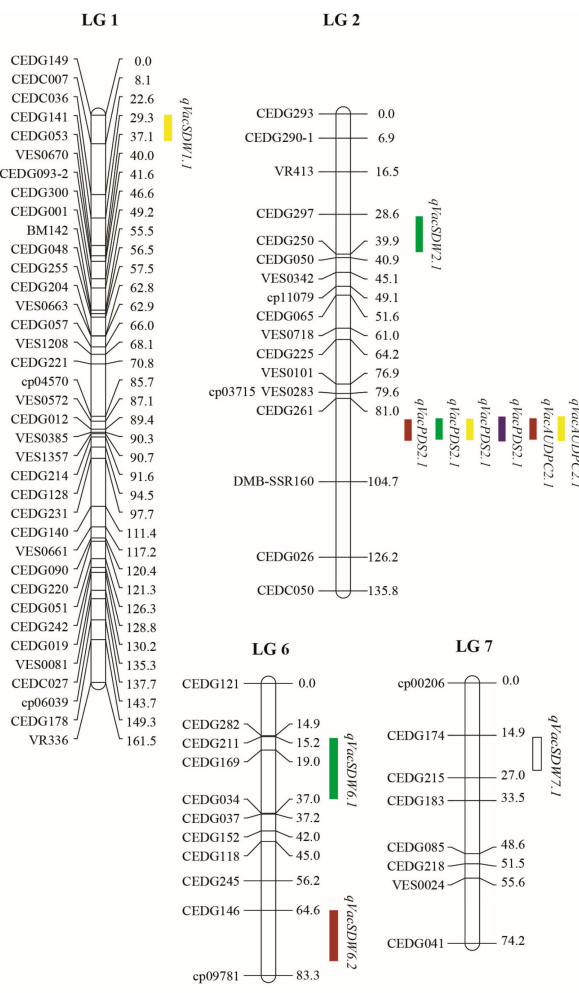

LG 3
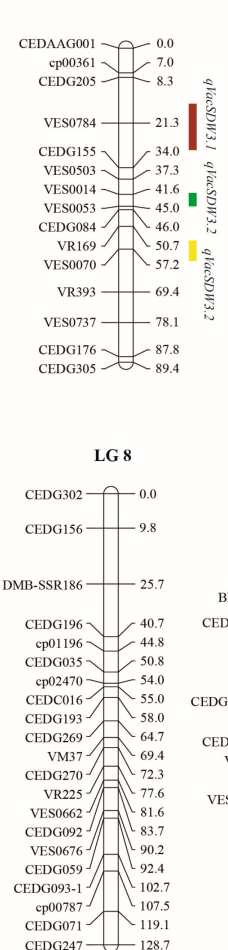

LG 4

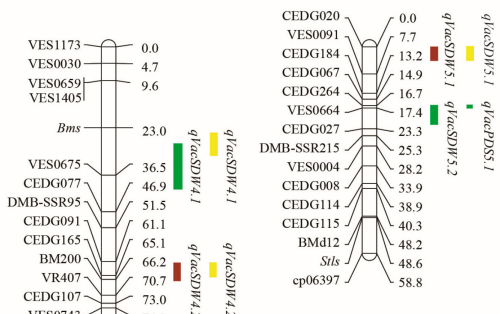

CEDG107 73.0 - 73.7

CEDG 103 74.3

$\left.\begin{array}{r}L s \\ \mathrm{AY} 1 \\ \mathrm{VES} 0102\end{array}\right] \begin{array}{r}87.6 \\ 92.1\end{array}$

CEDG011

CEDG011
CEDG127
VES0547 $\underbrace{109.2}_{112.0}$

LG 9

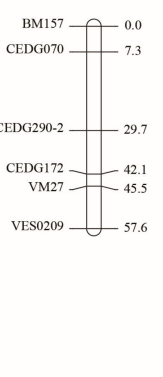

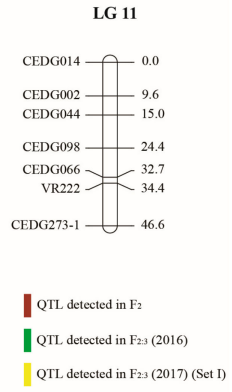

QTL detected in F23 (2017) (Set II)

Figure 3. Linkage map showing the location of Quantitative trait loci (QTLs) for percentage of damaged seeds and the AUDPC caused by Callosobruchus chinensis and for 100-seed weight in moth bean $\mathrm{F}_{2}$ and $\mathrm{F}_{2: 3}$ populations derived from the cross IPCMO056 $\times$ TN67. The QTLs were detected by inclusive composite interval mapping (ICIM).

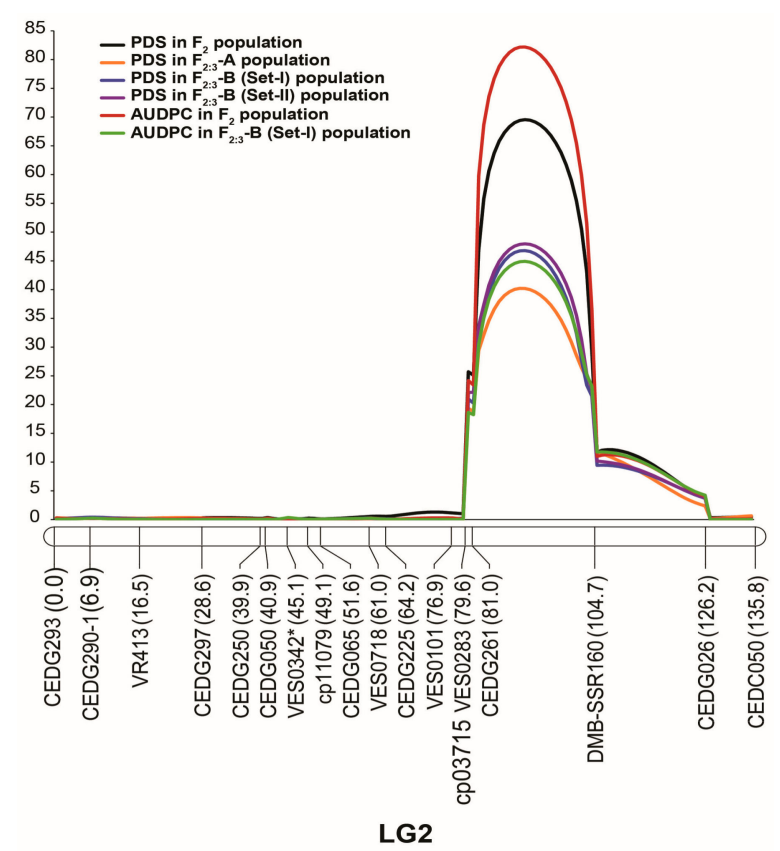

Figure 4. Logarithm of odds (LOD) graph of QTLs for percentage of damaged seeds (PDS) and the AUDPC on linkage group 2 detected by ICIM in moth bean $F_{2}$ and $F_{2: 3}$ populations derived from the cross TN67 $\times$ IPCMO056. 


\subsection{Comparison of QTLs for Bruchid Resistance}

Quantitative trait loci $q \operatorname{VacBrc2} .1$ for C. chinensis resistance, detected in moth bean on LG2, was compared with QTLs for bruchid (C. chinensis and/or C. maculatus) resistance mapped to LG2 in mungbean ( $V$. radiata) [20,24], wild azuki bean ( $V$. nepalensis) [8], black gram [25], and rice bean [23] even though only a small number of markers were common among linkage maps. BLASTN analysis revealed that genome conservation between moth bean and azuki bean/mungbean, especially azuki bean, was generally very high (Table S1). According to the QTL comparison, QTL qVacBrc2.1 in moth bean was similar to two QTLs in V. nepalensis, namely, Brc1.2.1 controlling the percentage of damaged seeds and Brcde1.2.1 contributing to the developmental period (days to emergence) of C. chinensis; however, $q \operatorname{VacBrc} 2.1$ was different from $q B r$, a QTL for the percentage of damaged seeds due to C. chinensis and C. maculatus in mungbean (Figure 5). The genomic location of $q V a c B r c 2.1$ differed from that of the QTL for C. maculatus resistance in rice bean (Figure 5). Although we were not able to clearly compare $q \operatorname{VacBrc} 2.1$ with the QTL for bruchid resistance in black gram because marker information was insufficient for the latter, $q \operatorname{VacBrc} 2.1$ may be identical to one of the three QTLs for C. maculatus resistance in black gram (Figure 5).

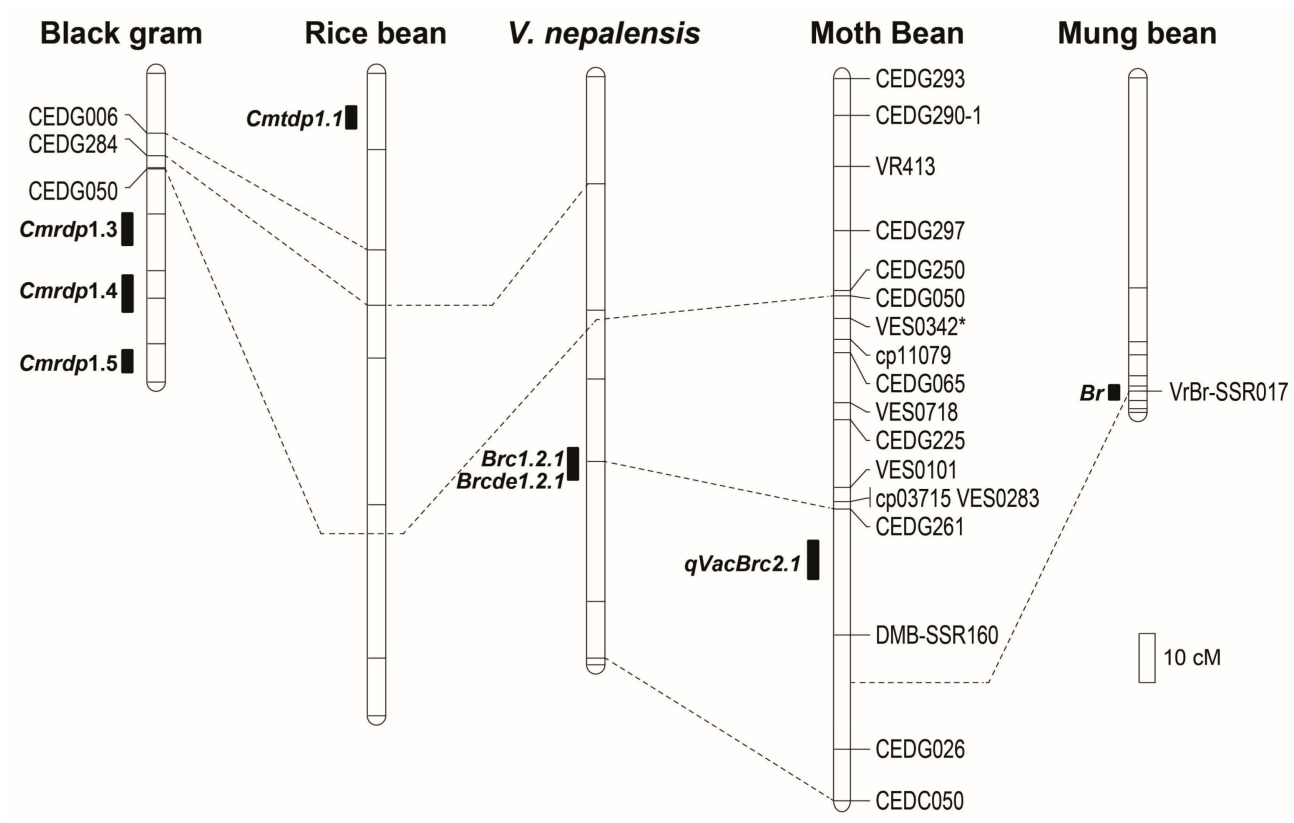

Figure 5. Comparative linkage map of QTLs for seed resistance to C. chinensis and Callosobruchus maculatus on linkage group 2 of moth bean (Vigna aconitifolia; this study), mungbean (Vigna radiata), azuki bean (Vigna nepalensis), black gram (Vigna mungo), and rice bean (Vigna umbellata). Dotted lines between maps connect common markers or indicate their possible positions.

\section{Discussion}

Postharvest seed loss due to bruchid infestation is a major problem in moth bean and other crops of the leguminous genus Vigna. Genetic study of bruchid resistance in Vigna crops, especially at the genome level, has been hindered because these species are minor or underutilized crops grown mainly in developing countries, with a corresponding lack of genomic resources. Recently, however, the whole genomes of mungbean and azuki bean were sequenced and released [21,22]. These resources are useful for genomics studies, both for these two species as well as their congeners, as genomes within Vigna are highly conserved [26]. Using QTL mapping and comparative genomic analysis, we were able to compare QTLs for bruchid resistance in different Vigna species.

The segregation analysis in this study suggested that seed resistance to $C$. chinensis in wild moth bean accession TN67 is controlled by a single dominant locus. This finding is similar to that of previous genetic studies of seed resistance to bruchids in mungbean, cowpea, and black gram, 
where bruchid resistance has been found to be a monogenic or oligogenic trait. In cultivated and wild mungbean, for example, resistance to $C$. chinensis and $C$. maculatus is controlled by a single dominant locus $(\mathrm{Br})[16,27]$, while resistance to $C$. maculatus in wild black gram is controlled by two dominant duplicated loci ( $\mathrm{Cmr} 1$ and $\mathrm{Cmr}$ ) [28]. In cultivated cowpea, resistance to C. maculatus is controlled by one or two recessive loci with modifiers [29]. In our study, QTL analysis uncovered two QTLs for C. chinensis resistance in moth bean accession TN67: a major QTL consistently identified in different generations and environments and a minor QTL detected in a specific environment (Table 3 and Figure 4). The results of our QTL analysis confirm the monogenic segregation for the resistance trait observed in the $\mathrm{F}_{2}$ and $\mathrm{F}_{2: 3}$ populations. Consequently, breeding $C$. chinensis-resistant moth bean cultivars should not be difficult. SSR markers CEDG261 and DMB-SSR160 may be used for marker-assisted selection to accelerate the development of such cultivars.

Some physical seed characteristics, such as seed size, have been reported to contribute to bruchid resistance. For example, QTL mapping for $C$. chinensis resistance in a wild azuki bean (V. nepalensis) clearly demonstrated a negative relationship between seed size and resistance [8]. In addition, QTL mapping demonstrated the colocalization of the $B r$ locus for bruchid resistance with a QTL for seed size in a wild mungbean [30]. In our study, the resistant parent (TN67) and the susceptible parent (IPCMO056) had contrasting seed sizes (1.23 vs. 2.65 g per 100 seeds, respectively). No significant correlation was observed between seed size and the percentage of damaged seeds or AUDPC (developmental period of $C$. chinensis) in the progenies derived from the two parents even though a minor QTL for bruchid resistance ( $q$ VacPDS5.1) and a minor QTL for seed size ( $q V a c S D W 5.2)$ were co-located (Figure 3). This lack of correlation indicates that seed size has no effect on C. chinensis resistance in moth bean TN67. The longer developmental period and lower percentage of damaged seeds observed in TN67 also indicate that the resistance is due to antibiosis in seeds rather than seed size or other seed characteristics. This result confirms that no association exists between seed size and resistance in TN67. Our findings in moth bean are the same as a previous determination in rice bean that QTLs for seed size do not associate with those for bruchid resistance [31].

Genome mapping studies of Vigna species, including mungbean, azuki bean, rice bean, black gram, and cowpea, have revealed that their genomes are highly similar. Genes/QTLs controlling the same traits in these species have been mapped to similar genomic regions; these mapped traits include seed size, days to flowering, seed dormancy, and pod length [26,32-35]. Genes/QTLs for bruchid resistance are similarly conserved among Vigna species, especially on LG2, where the QTL for resistance in mungbean [20,24], V. nepalensis [8], black gram [25], and rice bean [23] has been found to reside. The results of our QTL mapping of $C$. chinensis resistance in moth bean TN67 (Figures 3 and 5) further highlight the strong conservation of this trait on the homologous chromosome. In Vigna species, the number and effects of QTLs/genes for bruchid resistance on LG2 are different: one locus (the $\mathrm{Br}$ locus) conferring very high or complete resistance to both $\mathrm{C}$. chinensis and $\mathrm{C}$. maculatus is present in mungbean $[20,24]$, three loci with partial resistance to only $C$. maculatus are found in black gram [25], one locus giving partial resistance to only C. maculatus is present in rice bean [23], and one locus responsible for partial resistance to only $C$. chinensis is found in $V$. nepalensis [8]. Our QTL mapping and genome comparison revealed one principal QTL, qVacBrc2.1, and one modifying QTL, $q \operatorname{VacBrc5}$.1, that confer $C$. chinensis resistance in moth bean. qVacBrc2.1 is likely identical to a QTL for $C$. chinensis resistance in Vigna nepalensis and possibly the same as one of three QTLs for $C$. maculatus resistance in wild black gram (Figure 5). Regardless of the identity of these QTLs, our results demonstrate the diverse genetic basis of resistance against Callosobruchus bruchids in Vigna. Our findings should be useful for sustainable breeding for resistance and also demonstrate the high potential of comparative genomic analysis for identifying genes controlling useful traits in Vigna, especially minor or underutilized species. 
Supplementary Materials: The following are available online at http:/ / www.mdpi.com/2073-4425/9/11/555/s1, Table S1: Location of DNA markers mapped to linkage group 2 (LG2) of moth bean F2 population (IPCMO056 $\times$ TN67) on the reference genome of mungbean ([21]; http://plantgenomics.snu.ac.kr) and azuki bean ([22]; http://viggs.dna.affrc.go.jp).

Author Contributions: Conceptualization, P.S. and X.C.; Methodology, P.S. and A.J.; Investigation, A.J., C.Y., X.Y., J.C., and N.T.; Formal analysis, P.S. and A.J.; Writing—original draft, P.S.; Writing—review \& editing, P.S.; Funding acquisition, X.C. and P.S.

Funding: This research was supported by the National Key Research and Development Program (Grant number 2016YFE0203800) from Ministry of Science and Technology, China.

Acknowledgments: We thank Liwen Bianji, Edanz Group China (www.liwenbianji.cn/ac), for editing the English text of a draft of this manuscript.

Conflicts of Interest: The authors declare no conflicts of interest. The founding sponsors had no role in the design of the study; in the collection, analyses, or interpretation of data; in the writing of the manuscript, and in the decision to publish the results.

\section{References}

1. Rees, D.P. Insects of Stored Products; CSIRO Publishing: Melbourne, Australia, 2004; pp. 39-46.

2. Talekar, N.S. Biology, damage and control of bruchid pests of mungbean. In Proceedings of the 2nd International Symposium on Mungbean, Bangkok, Thailand, 16-20 November 1987; Shanmugasundaram, S., McLean, B.T., Eds.; AVRDC: Tainan, Taiwan, 1988; pp. 329-342.

3. Srinives, P.; Somta, P.; Somta, C. Genetics and breeding of resistance to bruchids (Callosobruchus spp.) in Vigna crops: A review. NU. Int. J. Sci. 2007, 4, 1-17.

4. Singh, S.R. Cowpea cultivars resistant to insect pests in world germplasm collection. Trop. Grain Legume Bull. 1977, 9, 1-7.

5. Fujii, K.; Miyazaki, S. Infestation resistance of wild legumes (Vigna sublobata) to azuki bean weevil, Callosobruchus chinensis (L.) (Coleoptera: Bruchidae) and its relationship with cytogenetic classification. Appl. Entomol. Zool. 1987, 22, 319-322. [CrossRef]

6. Talekar, N.S.; Lin, C.P. Characterization of Callosobruchus chinensis (Coleoptera: Bruchidae) resistance in mungbean. J. Econ. Entomol. 1992, 85, 1150-1153. [CrossRef]

7. Lambrides, C.J.; Imrie, B.C. Susceptibility of mungbean varieties to the bruchid species Callosobruchus maculatus (F.), C phaseoli (Gyll.), C chinensis (L.), and Acanthoscelides obtectus (Say) (Coleoptera: Chrysomelidae). Aust. J. Agric. Res. 2000, 51, 85-89. [CrossRef]

8. Somta, C.; Somta, P.; Tomooka, N.; Ooi, P.A.C.; Vaughan, D.A.; Srinives, P. Characterization of new sources of mungbean (Vigna radiata (L.) Wilczek) resistance to bruchids., Callosobruchus spp. (Coleoptera: Bruchidae). J. Stored Prod. Res. 2008, 44, 316-321. [CrossRef]

9. Vaughan, D.A.; Tomooka, N.; Kaga, A. Adzuki bean (Vigna angularis (Willd.) Ohwi \& Ohashi). In Genetic Resources, Chromosome Engineering, and Crop Improvement; Singh, R.J., Pauhar, P.P., Eds.; Taylor and Francis Group LLC: Boca Raton, FL, USA, 2005; pp. 347-359.

10. Somta, P.; Kaga, A.; Tomooka, N.; Isemura, T.; Vaughan, D.A.; Srinives, P. Mapping of quantitative trait loci for a new source of resistance to bruchids in the wild species Vigna nepalensis Tateishi and Maxted (Vigna subgenus Ceratotropis). Theor. Appl. Genet. 2008, 117, 621-627. [CrossRef] [PubMed]

11. Blink, M.; Jansen, P.C.M. Vigna aconitifolia (Jaqc.) Maréchal. In Plant Resources of Tropical Africa 1: Cereals and Pulses; Blink, M., Belay, G., Eds.; PROTA Foundation/Backhuys Publisher/CTA: Wageningen, The Netherlands, 2006; pp. 200-203.

12. Van Oers, C.C.C.M. Vigna aconitifolia (Jaqc.) Maréchal. In Plant Resources of South-East Asia 1: Pulses; Maesen, V.D., Somaatmadja, S., Eds.; PROSEA Foundation: Bogor, Indonesia, 1992; pp. 66-67.

13. Kumar, D. Production Technology for Moth Bean in India; Indian Turisum Publication: Jodhpur, India, 2002; pp. 1-29.

14. Tomooka, N.; Kashiwaba, K.; Vaughan, D.A.; Ishimoto, M.; Egawa, Y. The effectiveness of evaluating wild species: Searching for sources of resistance to bruchids beetles in the genus Vigna subgenus Ceratotropis. Euphytica 2000, 115, 27-41. [CrossRef] 
15. Yundaeng, C.; Somta, P.; Amkul, K.; Kongjaimun, K.; Kaga, A.; Pandiyan, M.; Natesan, S.; Tomooka, N. Construction of genetic linkage map and genome dissection of domestication related traits of moth bean (Vigna aconitifolia), a legume crop of arid areas. Mol. Genet. Genom. 2018. submitted.

16. Somta, P.; Ammaranan, C.; Ooi, P.A.C.; Srinives, P. Inheritance of seed resistance to bruchids in cultivated mungbean (Vigna radiata L. Wilczek). Euphytica 2007, 155, 47-55. [CrossRef]

17. Van der Plank, J.E. Plant Diseases: Epidemics and Control; Academic Press: New York, NY, USA, 1963; pp. 1-349.

18. R Development Core Team. R: A Language and Environment for Statistical Computing; R Foundation for Statistical Computing: Vienna, Austria, 2013.

19. Li, H.; Ye, G.; Wang, J. A modified algorithm for the improvement of composite interval mapping. Genetics 2007, 175, 361-374. [CrossRef] [PubMed]

20. Chotechung, S.; Somta, P.; Chen, J.; Yimram, T.; Chen, X.; Srinives, P. A gene encoding a polygalacturonase-inhibiting protein (PGIP) is a candidate gene for bruchid (Coleoptera: Bruchidae) resistance in mungbean (Vigna radiata). Theor. Appl. Genet. 2016, 129, 1673-1683. [CrossRef] [PubMed]

21. Kang, Y.J.; Kim, S.; Kim, M.Y.; Lestari, P.; Kim, K.H.; Ha, B.K.; Jun, T.H.; Hwang, W.J.; Lee, T.; Lee, J.; et al. Genome sequence of mungbean and insights into evolution within Vigna species. Nat. Commun. 2014, 5, 5443. [CrossRef] [PubMed]

22. Sakai, H.; Naito, K.; Ogiso-Tanaka, E.; Takahashi, Y.; Iseki, K.; Muto, C.; Satou, K.; Teruya, K.; Shiroma, A.; Shimoji, M.; et al. The power of single molecule real-time sequencing technology in the de novo assembly of a eukaryotic genome. Sci Rep. 2015, 5, 16780. [CrossRef] [PubMed]

23. Venkataramana, P.B.; Gowda, R.; Somta, P.; Ramesh, S.; Rao, A.M.; Bhanuprakash, K.; Srinives, P.; Gireesh, C.; Pramila, C.K. Mapping QTL for bruchid resistance in rice bean (Vigna umbellata). Euphytica 2016, 207, 135-147. [CrossRef]

24. Kaewwongwal, A.; Chen, J.; Somta, P.; Kongjaimun, A.; Yimram, T.; Chen, X.; Srinives, P. Novel alleles of two tightly linked gene encoding polygalacturonase-inhibiting proteins (VrPGIP1 and VrPGIP2) associated with the $\mathrm{Br}$ locus that confer bruchid (Callosobruchus spp.) resistance to mungbean (Vigna radiata) accession V2709. Front. Plant Sci. 2017, 8, 1692. [CrossRef] [PubMed]

25. Souframanien, J.; Gupta, S.K.; Gopalakrishna, T. Identification of quantitative trait loci for bruchid (Callosobruchus maculatus) resistance in black gram [Vigna mungo (L.) Hepper]. Euphytica 2010, 176, 349-356. [CrossRef]

26. Kaga, A.; Isemura, T.; Shimizu, T.; Somta, P.; Srinives, P.; Tabata, S.; Tomooa, N.; Vaughan, D.A. Asian Vigna genome research. In Proceedings of the 14th NIAS International Workshop on Genetic Resources: Genetic Resources and Comparative Genomics of Legumes (Glycine and Vigna), Tsukuba, Japan, 14 September 2009; Tomooka, N., Vaughan, D.A., Eds.; National Institute of Agrobiological Sciences: Tsukuba, Japan, 2011; pp. 33-39.

27. Kitamura, K.; Ishimoto, M.; Sawa, M. Inheritance of resistance to infestation with azuki bean weevil in Vigna sublobata and successful incorporation to V. radiata. Jpn. J. Breed. 1988, 38, 459-464. [CrossRef]

28. Dongre, T.K.; Pawar, S.E.; Thakare, R.G.; Harwalkar, M.R. Identification of resistant source to cowpea weevil (Callosobruchus maculatus (F.)) in Vigna sp. and inheritance of their resistance in black gram (Vigna mungo var. mungo). J. Stored Prod. Res. 1996, 32, 201-204. [CrossRef]

29. Redden, R.J.; McGuire, J. The genetic evaluation of bruchid resistance in seed of cowpea. Aust. J. Agric. Res. 1983, 34, 707-715. [CrossRef]

30. Mei, L.; Cheng, X.Z.; Wang, S.H.; Wang, L.X.; Liu, C.Y.; Sun, L.; Xu, N.; Humphry, M.E.; Lambrides, C.J.; Li, H.B.; et al. Relationship between bruchid resistance and seed mass in mungbean based on QTL analysis. Genome 2009, 52, 589-596. [CrossRef] [PubMed]

31. Somta, P.; Kaga, A.; Tomooka, N.; Kashiwaba, K.; Isemura, K.; Chaitieng, B.; Srinives, P.; Vaughan, D.A. Development of an interspecific Vigna linkage map between Vigna umbellata (Thunb.) Ohwi \& Ohashi and $V$. nakashimae (Ohwi) Ohwi \& Ohashi and its use in analysis of bruchid resistance and comparative genomics. Plant Breed. 2006, 125, 77-84. [CrossRef]

32. Isemura, T.; Kaga, A.; Konishi, S.; Ando, T.; Tomooka, N.; Han, O.K.; Vaughan, D.A. Genome dissection of traits related to domestication in azuki bean (Vigna angularis) and comparison with other warm season legumes. Ann. Bot. 2007, 100, 1053-1071. [CrossRef] [PubMed]

33. Isemura, T.; Kaga, A.; Tomooka, N.; Shimizu, T.; Vaughan, D.A. The genetics of domestication of rice bean, Vigna umbellata. Ann. Bot. 2010, 106, 927-944. [CrossRef] [PubMed] 
34. Isemura, T.; Kaga, A.; Tabata, S.; Somta, P.; Srinives, P.; Shimizu, T.; Jo, U.; Vaughan, D.A.; Tomooka, N. Construction of a genetic linkage map and genetic analysis of domestication related traits in mungbean (Vigna radiata). PLoS ONE 2012, 7, e41304. [CrossRef] [PubMed]

35. Kongjaimun, A.; Kaga, A.; Tomooka, N.; Somta, P.; Shimizu, T.; Shu, Y.; Isemura, T.; Vaughan, D.A.; Srinives, P. An SSR-based linkage map of yardlong bean (Vigna unguiculata ssp. sesquipedalis (L.) Verc.) and QTL analysis of pod length. Genome 2012, 55, 81-92. [CrossRef]

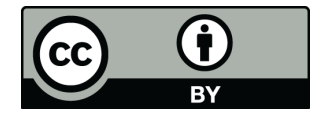

(C) 2018 by the authors. Licensee MDPI, Basel, Switzerland. This article is an open access article distributed under the terms and conditions of the Creative Commons Attribution (CC BY) license (http:/ / creativecommons.org/licenses/by/4.0/). 